\title{
ToF-SIMS Imaging Study of the Early Stages of Corrosion in Al-Cu Thin Films
}

\author{
A. Seyeux ${ }^{\text {a,z }}$ G. S. Frankel,,${ }^{b, *}$ N. Missert,,${ }^{c, * *}$ K. A. Unocic, ${ }^{d}$ L. H. Klein, ${ }^{a}$ A. Galtayries, ${ }^{a}$ \\ and P. Marcus, ${ }^{\text {a,z }}$ \\ ${ }^{a}$ Laboratoire de Physico-Chimie des Surfaces, Ecole Nationale Supérieure de Chimie de Paris, Chimie ParisTech, \\ ENSCP/CNRS (UMR 7045), Paris 75005, France \\ ${ }^{b}$ The Ohio State University, Columbus, Ohio 43210, USA \\ 'Sandia National Laboratories, Albuquerque, New Mexico 87185, USA \\ ${ }^{d}$ Oak Ridge National Laboratory, Oak Ridge, Tennessee 37381, USA
}

\begin{abstract}
The pitting corrosion of $\mathrm{Al}-\mathrm{Cu}$ thin film alloys was investigated using samples that were heat treated in air to form through-thickness $\mathrm{Al}_{2} \mathrm{Cu}$ particles within an $\mathrm{Al}-0.5 \% \mathrm{Cu}$ matrix. Time-of-Flight Secondary Ion Mass Spectroscopy (ToF-SIMS) analysis revealed $\mathrm{Cu}$-rich regions $250-800 \mathrm{~nm}$ in lateral extent near the metal/oxide interface. Following exposure that generated pitting corrosion, secondary electron, secondary ion, and AFM images showed pits with size and density similar to those of the Cu-rich regions. The role of the $\mathrm{Cu}$-rich regions is addressed.

(C) 2011 The Electrochemical Society. [DOI: 10.1149/1.3568944] All rights reserved.
\end{abstract}

Manuscript submitted November 23, 2010; revised manuscript received February 23, 2011. Published March 31, 2011.

Aluminium alloys are widely used in aerospace applications due to their very good mechanical properties, low densities and good uniform corrosion resistance. Copper is one of the most common alloying elements and a variety of alloys in which copper is the major addition have been developed. Due to the low solid solubility of copper in aluminium, the aging of $\mathrm{Al}-\mathrm{Cu}$ alloys under high temperature conditions leads to the formation of intermetallic $\mathrm{Cu}$-rich particles, including $\theta$-phase $\mathrm{Al}_{2} \mathrm{Cu}$, that are known to lead to pitting corrosion susceptibility in aqueous chloride environments. ${ }^{1-12}$

The $\mathrm{Cu}$-rich particles in $\mathrm{Al}$ alloys can play several roles that might promote localized corrosion. They are known to have higher potentials than the bulk matrix so that galvanic interaction with the matrix might increase the local potential above the breakdown potential. ${ }^{3,4,6,10,11,13-15}$ The oxide on these particles might be more conductive or catalytic, thereby providing more cathodic current from oxygen reduction that can drive localized corrosion. $^{3,4,11,13,15,16}$ The local higher rate of oxygen reduction can lead to local $p \mathrm{H}$ changes that attack the neighboring matrix, causing trenching and/or $\mathrm{Cu}$ enrichment. ${ }^{12,17-19}$ The interface between particles and matrix can also provide initiation sites for localized attack due to local disorder at the phase boundary. ${ }^{20}$

Model thin film alloys with nanoscale surface roughness allow a detailed investigation of local morphology, microstructure and composition that may influence pit initiation. Thin film and bulk $\mathrm{Al}-\mathrm{Cu}$ alloys were used as model samples in this work. Prior experiments on thin film $\mathrm{Al}-\mathrm{Cu}$ samples found that rapid anodic corrosion of the matrix could be initiated at the open circuit potential at a pre-existing defect in a near neutral solution of $0.01 \mathrm{M} \mathrm{NaCl}+0.3 \%$ vol $\mathrm{H}_{2} \mathrm{O}_{2}$. Pitting corrosion near the theta phase intermetallic particles was observed in the cathodic regions where the $p H$ increased as evidenced by confocal scanning laser microscopy in the presence of a $p \mathrm{H}$ indicator. However, pitting corrosion was observed only at some of the particles in the high $\mathrm{pH}$ region. ${ }^{21}$

Time-of-Flight Secondary Ion Mass Spectroscopy (ToF-SIMS) was used in this study to investigate whether compositional heterogeneities existed in the oxide covering the $\mathrm{Al}_{2} \mathrm{Cu}$ particles or the matrix, in both thin film and bulk samples. The goal was to assess whether compositional heterogeneity in the oxide above the particles could be related to differences in local reactivity. Although XPS and Auger spectroscopies have been previously used to observe the presence of metallic $\mathrm{Cu}$ in the oxide above model $\mathrm{Al}_{2} \mathrm{Cu}$ alloys, ${ }^{4,13}$ the sensitivity of these techniques and the spatial

\footnotetext{
* Electrochemical Society Fellow.

** Electrochemical Society Active Member.

2E-mail: antoine-seyeux@chimie-paristech.fr; philippe-marcus@chimieparistech.fr
}

resolution of XPS are limited. Recent ToF-SIMS imaging of $\mathrm{Cu}$ in corrosion product surrounding intermetallic particles in $\mathrm{Al}$ alloys has allowed the spatial extent of $\mathrm{Cu}$ redistribution to be measured. ${ }^{22}$

\section{Experimental}

Material synthesis and exposures.-The thin films were prepared by depositing $100 \mathrm{~nm}$ of $\mathrm{Al}-\mathrm{Cu}$ (with $\mathrm{Cu}$ content equal to 3.5 or $7 \mathrm{wt} \%$ ) on $\mathrm{SiO}_{2} / \mathrm{Si}$ substrates. The deposition treatment consisted of electron-beam co-evaporation from $99.9999 \% \mathrm{Al}$ and $99.99 \% \mathrm{Cu}$ sources at room temperature with the rates adjusted and to give the desired composition. A surface oxide layer was formed by exposure to pure oxygen for several hours. Samples were then aged in air at $300^{\circ} \mathrm{C}$ for $10 \mathrm{~h}$ followed by $450^{\circ} \mathrm{C}$ for $5 \mathrm{~min}$ in order to form $\mathrm{Al}_{2} \mathrm{Cu}$ intermetallic particles in an $\mathrm{Al}-0.5 \mathrm{wt} \% \mathrm{Cu}$ matrix.

A bulk sample of Al-Cu alloy was investigated for comparison. The alloy was melted from pure alloy stock and contained $4 \mathrm{wt} \%$ $\mathrm{Cu}$. It was heated at $560^{\circ} \mathrm{C}$ for $1 \mathrm{~h}$ to create a homogeneous $\mathrm{Al}-\mathrm{Cu}$ solid solution, water quenched, polished to $1 \mu \mathrm{m}$ diamond paste, and then aged in air using the same temperatures and times described above.

Thin film samples were analyzed by ToF-SIMS in one of three conditions: (a) thermal treatment only, (b) 30 min immersion at the open-circuit potential to a near neutral electrolyte containing $0.01 \mathrm{M}$ $\mathrm{NaCl}+0.3 \%$ vol $\mathrm{H}_{2} \mathrm{O}_{2}$ where pitting was not initiated at a pre-existing defect, and (c) $30 \mathrm{~min}$ immersion at the open-circuit potential to $0.01 \mathrm{M} \mathrm{NaCl}$ with the $p \mathrm{H}$ adjusted to 11.5 with $\mathrm{NaOH}$ in order to obtain the same pitting morphology previously observed in cathodic regions of the electrode during rapid anodic pitting at a pre-existing defect. $^{21}$ These samples will be referred to as A, B, and C throughout the manuscript. ToF-SIMS analysis of the bulk sample was also performed, and will be referred to as sample D. Note that identical corrosion morphology was observed for both $\mathrm{Al}-3.5 \% \mathrm{Cu}$ and $\mathrm{Al}-$ $7 \% \mathrm{Cu}$ thin films exposed to $p \mathrm{H} \mathrm{11.5}$. For 30-min exposures, the oxide remained passive except for localized pitting.

ToF-SIMS, AFM, and FIB analyses.-ToF-SIMS analyses were performed using a ToF-SIMS V spectrometer (ION TOF GmbH Munster, Germany). The analysis chamber was maintained at less than $1.10^{-9} \mathrm{~Pa}$. A pulsed $25 \mathrm{keV} \mathrm{Bi}^{+}$primary ion source was employed for analysis. The total primary ion flux was below $10^{12}$ ions $/ \mathrm{cm}^{2}$ to ensure static conditions. Depth profiles were acquired using a $\mathrm{Cs}^{+}$sputter beam. Data acquisition and post-processing analyses were performed using the Ion-Spec commercial software.

Atomic Force Microscopy (AFM) imaging in acoustic AC mode (i.e. tapping mode in which the tip is excited in acoustic way at its resonance frequency) was performed in air, at room temperature using a Agilent 5100 microscope (Agilent Technologies). Topographic AFM 

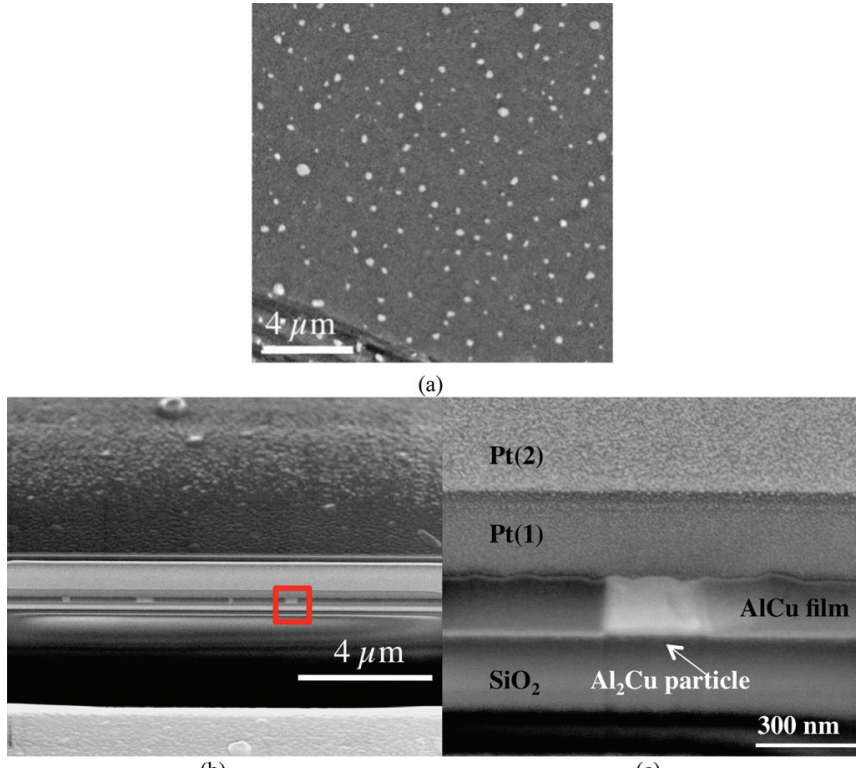

(b)

(c)

Figure 1. (Color online) SEM micrographs of an Al-3.5 wt \% Cu thin film after the thermal treatment. (a) Top view showing distribution of sub-micron $\mathrm{Al}_{2} \mathrm{Cu}$ particles (b) FIB cross-section of film (c) detailed view of the area marked on (b).

images of the surface were acquired (mapping of the relief of the surface in $\mathrm{x}, \mathrm{y}$ and $\mathrm{z}$ directions). Stiff SiN type cantilevers from Applied Nanostructures, with a force constant of $50 \mathrm{~N} / \mathrm{m}$ and a tip radius lower than $10 \mathrm{~nm}$ were employed.

Cross sections and SEM images of the thin films were obtained with a FEI Helios Nanolab 600, while the bulk sample sectioning and imaging was performed using a FEI Nova 600 dual beam focus ion beam (FIB) instrument. In both cases, the surface of the sample was protected from damage due to $\mathrm{Ga}$ ion milling by depositing a thin Pt layer.
Results

Thin film samples.-As shown in Fig. 1a, the thin film samples exhibited a microstructure after aging that consisted of a distribution of $\mathrm{Al}_{2} \mathrm{Cu}$ ( $\theta$ phase) particles in an Al-rich matrix that had less than $0.5 \% \mathrm{Cu}$ according to EDS measurements. Figures $1 \mathrm{~b}$ and $1 \mathrm{c}$ show SEM micrographs of a FIB cross section cut in the deposited layer. The particles were through-thickness, and had diameters ranging between $\sim 20$ and $300 \mathrm{~nm}$. They were identified as $\mathrm{Al}_{2} \mathrm{Cu}$ by selected area electron diffraction analysis obtained on plan view TEM specimens.

The thin film sample $\mathrm{B}$, which was exposed to near neutral 0.01 $\mathrm{M} \mathrm{NaCl}+0.3 \%$ vol $\mathrm{H}_{2} \mathrm{O}_{2}$ for 30 min after the thermal treatment, did not exhibit evidence of localized corrosion. Pitting corrosion was observed for the sample $\mathrm{C}$, which was exposed for $30 \mathrm{~min}$ to $0.01 \mathrm{M} \mathrm{NaCl}$ adjusted to $p \mathrm{H} \mathrm{11.5}$. The $p \mathrm{H}$ was increased in this exposure to simulate the environment expected in the high $p \mathrm{H}$ cathodic regions.

Figure 2 presents a typical ToF-SIMS negative ion depth profile of the unexposed sample A. The depth profile observed for sample $\mathrm{B}$ was almost identical. In Fig. 2, the counts associated with the Alcontaining ions $\left(\mathrm{Al}^{-}, \mathrm{AlO}^{-}, \mathrm{AlO}_{2}^{-}, \mathrm{Al}_{2}^{-}\right)$, Si-containing ions $\left(\mathrm{Si}^{-}\right.$, $\left.\mathrm{SiO}_{2}^{-}\right),{ }^{63} \mathrm{Cu}^{-}, \mathrm{OH}^{-}$and ${ }^{18} \mathrm{O}^{-}$ions, all recorded simultaneously, are plotted versus $\mathrm{Cs}^{+}$ion sputtering time. The ${ }^{16} \mathrm{O}^{-}$intensity saturated the detector, so the signal of the isotope ${ }^{18} \mathrm{O}^{-}$is plotted instead. The $\mathrm{AlO}_{2}^{-}$and $\mathrm{Al}_{2}^{-}$signals are representative of the aluminium oxide and the metallic substrate, respectively. Note that the intensity is reported using a logarithmic scale, which emphasizes the low intensity signals. The changes in secondary ion (SI) intensity with the sputter time reflect in-depth variations in concentration, but they are also strongly dependent on the matrix from which the ions are emitted.

Three main regions can be identified in Fig. 2. The first one, corresponding to the first $40 \mathrm{~s}$ of sputtering, is characterized by high intensity and relatively constant $\mathrm{AlO}^{-}, \mathrm{AlO}_{2}^{-}$and ${ }^{18} \mathrm{O}^{-}$signals. This region is assigned to the presence of an oxide film formed on the deposited alloy film after exposure to oxygen for several hours and exposure to air during the thermal treatment. $\mathrm{No}^{-} \mathrm{CuO}^{-}$(not shown on Fig. 2 for clarity) or $\mathrm{Cu}^{-}$signal can be detected in this region,

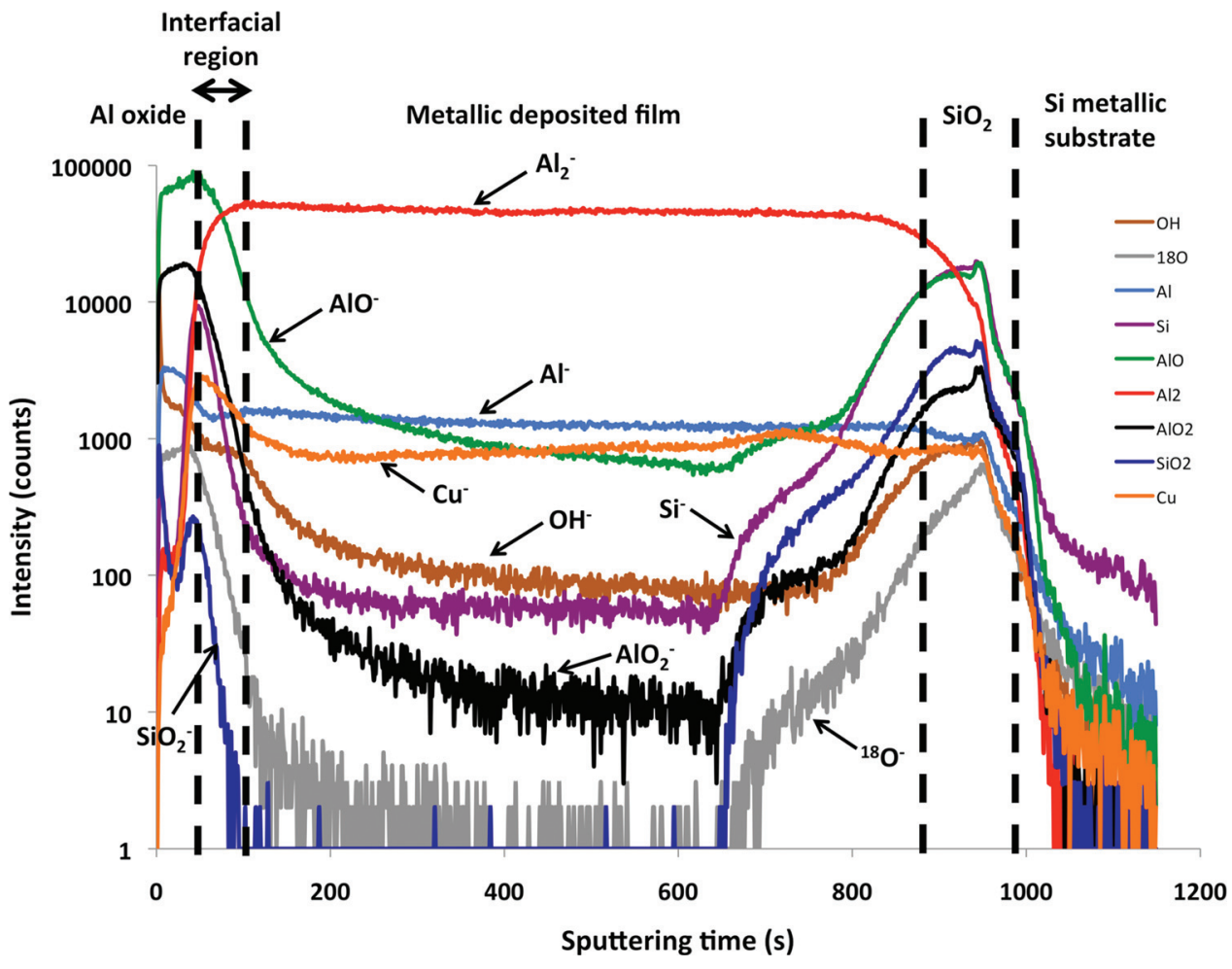

Figure 2. (Color online) ToF-SIMS negative ion depth profile obtained on thin film Al-3.5 wt \% Cu sample A. The oxide film, the metallic film and the Si substrate are indicated on the profile. 
which indicates that an aluminium oxide layer $\left(\mathrm{Al}_{2} \mathrm{O}_{3}\right)$ is formed. Note that in this approach, the signal is from an area of $100 \times 100$ $\mu \mathrm{m}^{2}$ with no further spatial resolution, so oxide above both the matrix and $\theta$ phases contributes to the total signal. The average thickness of the aluminium oxide film can be estimated to be $7 \mathrm{~nm}$ assuming an oxide density of $2.34 \times 10^{22}$ atom $\mathrm{cm}^{-3}$ and a sputter yield of $\sim 1.5$, which is the sputter yield of metallic Al. After about the first $40 \mathrm{~s}$ of sputtering, the intensities of the $\mathrm{AlO}^{-}, \mathrm{AlO}_{2}^{-}$and ${ }^{18} \mathrm{O}^{-}$ions start to decrease and the $\mathrm{Al}_{2}^{-}$intensity signal increases drastically indicating the start of the $\mathrm{Al}$ oxide/metallic $\mathrm{Al}$ deposited film interface region in the depth profile that is mainly due to the surface roughness. After another $40 \mathrm{~s}$ of sputtering, the large and constant $\mathrm{Al}_{2}^{-}$signal indicates the second region associated with the metallic deposited layer. After about $875 \mathrm{~s}$ of total sputtering, the $\mathrm{Al}_{2}^{-}$intensity signal starts to drop, whereas $\mathrm{Si}$ signals $\left(\mathrm{Si}^{-}\right.$and $\left.\mathrm{SiO}_{2}^{-}\right)$and ${ }^{18} \mathrm{O}^{-}$signal reach high intensity. This indicates that the metallic deposited film/Si substrate interface is reached (the position of the interface and thus the thickness of the metallic deposited film can be estimated from the intensity plateau on the $\mathrm{Al}_{2}^{-}$signal). The high $\mathrm{SiO}_{2}^{-}$signal that reaches its maximum intensity after around $950 \mathrm{~s}$ of total sputtering indicates that a thin layer of silicon oxide covers the Si substrate. After $980 \mathrm{~s}$ of sputtering, one enters the Si substrate.

Figure 2 shows a clear peak in the ${ }^{63} \mathrm{Cu}^{-}$signal at the oxide/ metal interface region before decreasing to the stable value in the metallic region. Note that no $\mathrm{CuO}^{-}$signal was observed, even within the metal/oxide interfacial region. This type of $\mathrm{Cu}$ enrichment at the metal-oxide interface has been previously observed on $\mathrm{Al}_{2} \mathrm{Cu}$ thin films ${ }^{23}$ and Al-low weight percent $\mathrm{Cu}$ thin films $\mathrm{s}^{24,25}$ using Rutherford backscattering. To investigate this region further, ToF-SIMS mapping was performed on samples A and B, which gave essentially the same result. Figure 3 shows $10 \times 10 \mu \mathrm{m}^{2}$ negative ion maps in high lateral resolution mode $\left(\mathrm{Bi}^{+}\right.$current: $\left.0.4 \mathrm{pA}\right)$ for sample B after (a) $0 \mathrm{~s}$, (b) $40 \mathrm{~s}$, and (c) $200 \mathrm{~s}$ of sputtering, which correspond to (a) the surface of the sample, (b) the interface between the oxide layer and the metallic substrate (at approximately $7 \mathrm{~nm}$ depth) and (c) inside the metallic substrate (at approximately
$30 \mathrm{~nm}$ depth), respectively. The images in Fig. 3a show no regions of varying intensity, indicating the formation of a homogeneous aluminium oxide film in the near surface region. However, as the metal/oxide interface is approached, isolated areas of higher ${ }^{63} \mathrm{Cu}^{-}$intensity, and some corresponding areas of low $\mathrm{Al}_{2}^{-}$intensity are detected, becoming more pronounced with increasing sputtering time. Figure $3 \mathrm{~b}$ shows the ion maps at the metal/oxide interface, with clear evidence for isolated $\mathrm{Cu}$-rich regions. These regions are approximately the same size as the $\theta$ phase particles seen in Fig. 1; they range between 250 and $800 \mathrm{~nm}$ in size with a density of about $0.5 \mu \mathrm{m}^{-2}$. As shown in Fig. 3c, no further evidence of localized $\mathrm{Cu}$ enrichment was obtained on ion images after sputtering beyond the metal/oxide interface, despite the fact that the particles are throughthickness, as shown in Figs. $1 \mathrm{~b}$ and $1 \mathrm{c}$.

Figure 4 presents two ToF-SIMS negative ion depth profiles of the $\mathrm{Al}-7 \% \mathrm{Cu}$ sample $\mathrm{C}$. The profile in Fig. 4a was recorded inside the exposed area and the profile in Fig. $4 \mathrm{~b}$ was recorded outside the exposed area. In both depth profiles, a sharp rise of the $\mathrm{Al}_{2}^{-}$signal intensity is observed after $75 \mathrm{~s}$ sputtering, indicating a similar oxide layer thickness for treated and non-treated areas. Nevertheless, inside the treated area a gradual increase of the $\mathrm{Al}_{2}^{-}$intensity signal between 75 and $500 \mathrm{~s}$ of sputtering and a slow decay of the $\mathrm{AlO}_{2}^{-}$intensity signal indicate that, in this region, the corrosion products that are formed inside the pits dominate the profile.

Secondary electron (SE) and secondary ion (SI) images of the exact same area of sample $\mathrm{C}$, both recorded from the ToF-SIMS spectrometer, are presented in Figs. 5a and 5b, respectively. Pits are clearly seen in the SE image as dark spots with a density of about $0.6 \mu \mathrm{m}^{-2}$. The ToF-SIMS SI maps in Fig. 5b indicate that the $\mathrm{Si}^{-}$, $\mathrm{O}^{-}, \mathrm{AlO}^{-}$and $\mathrm{AlO}_{2}^{-}$ion intensities are higher at the exact locations of the dark spots in the SE image. The higher $\mathrm{Si}^{-}$intensity in the pits indicates that the pits have reached the $\mathrm{SiO}_{2} / \mathrm{Si}$ substrate (white arrows). The high intensities of $\mathrm{O}^{-}, \mathrm{AlO}^{-}$and $\mathrm{AlO}_{2}^{-}$ions (white arrows) suggest that the pits contain corrosion products that are mainly aluminium oxide or hydroxide, as previously stated from the

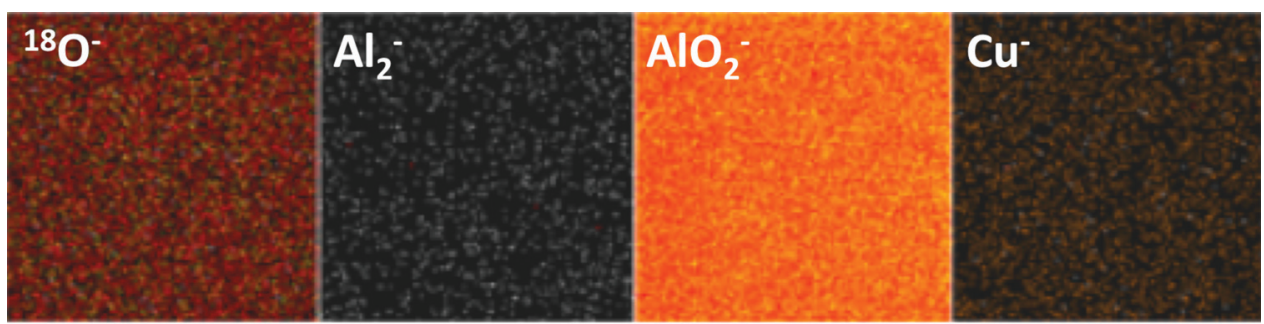

(a)

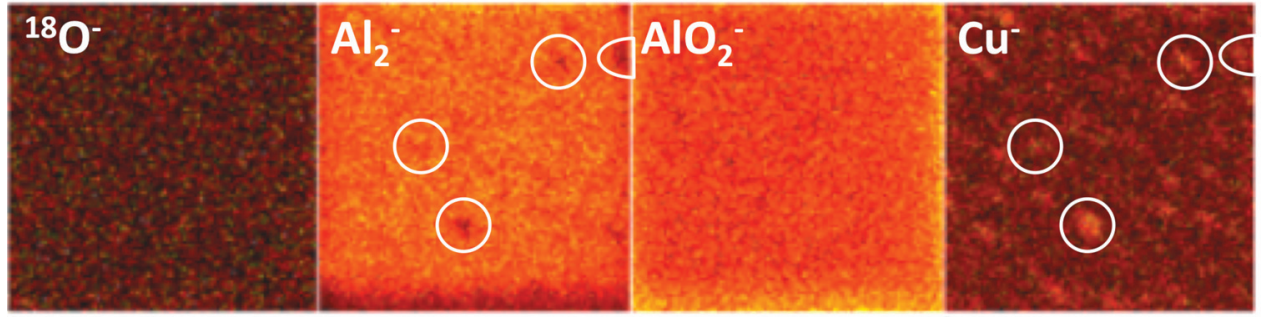

(b)

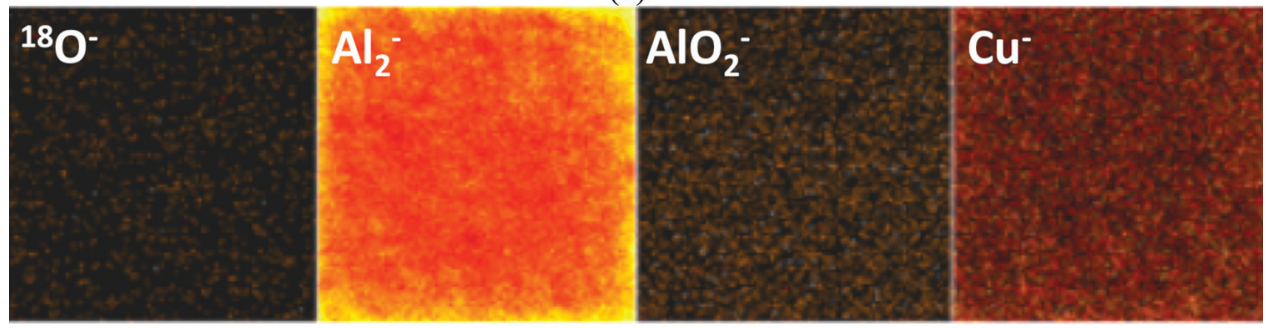

(c)
Figure 3. (Color online) ToF-SIMS negative ion images of ${ }^{18} \mathrm{O}^{-}, \mathrm{Al}_{2}^{-}, \mathrm{AlO}_{2}^{-}$and $\mathrm{Cu}^{-}$recorded on the thin film $\mathrm{Al}-3.5 \mathrm{wt} \%$ Cu sample B after (a) $0 \mathrm{~s}$, (b) $40 \mathrm{~s}$, and (c) $200 \mathrm{~s}$ of sputtering. Regions of $\mathrm{Cu}$ enrichment and $\mathrm{Al}$ depletion are circled in (b) for clarity. 


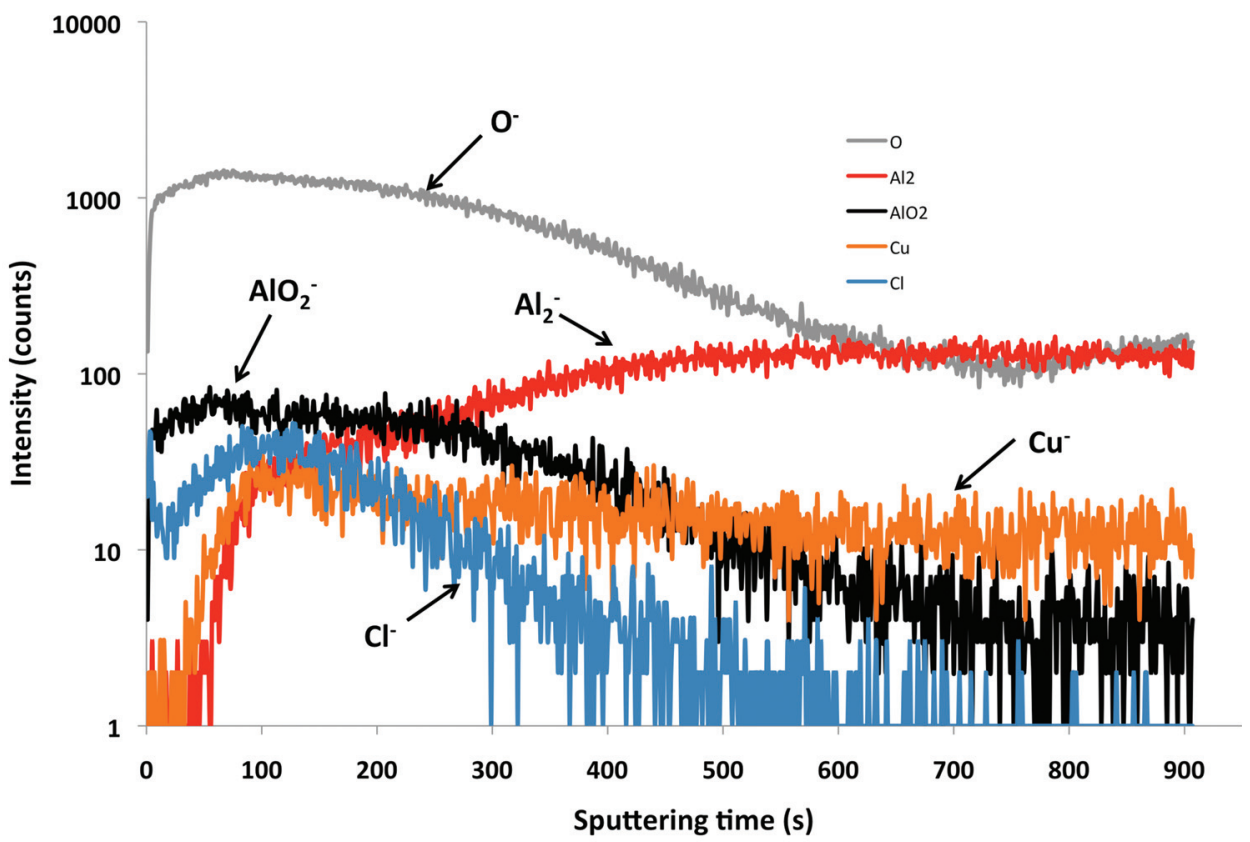

(a)

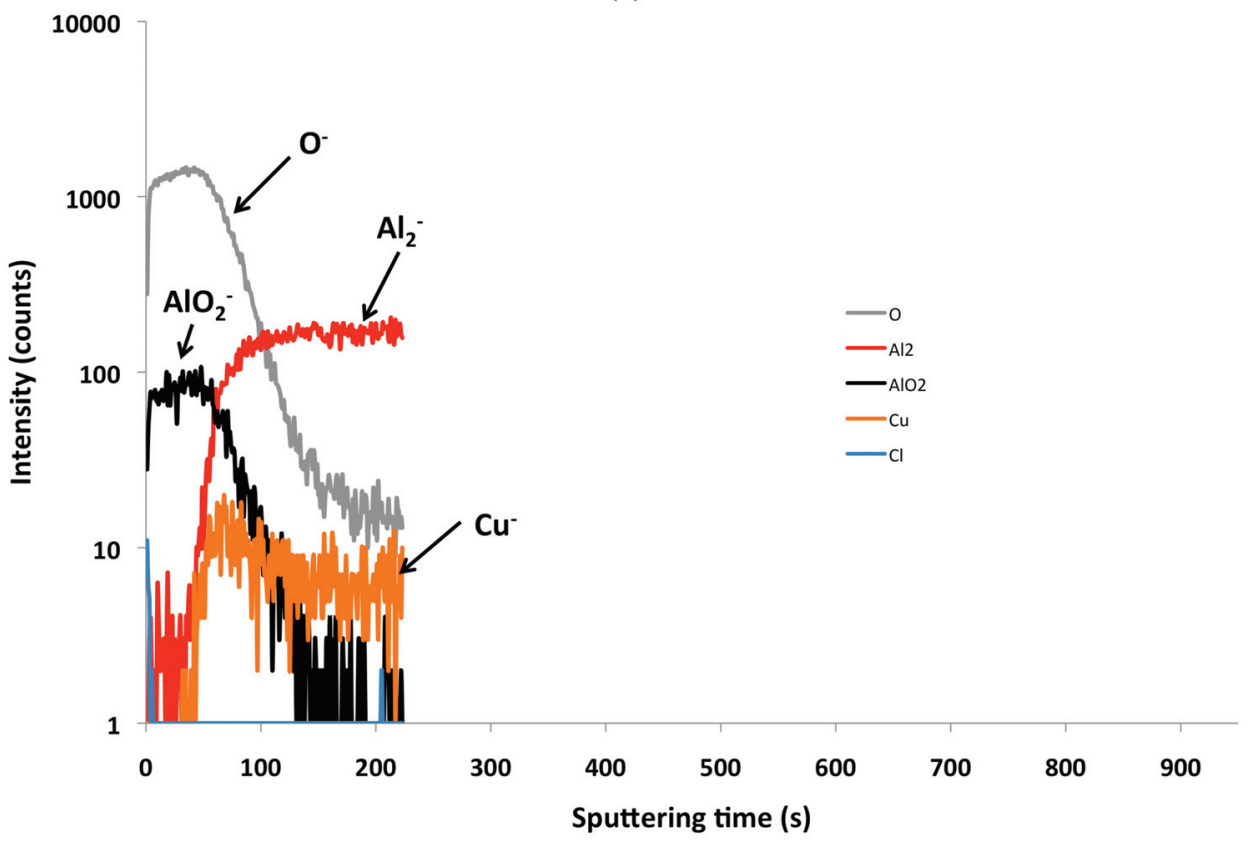

Figure 4. (Color online) ToF-SIMS negative ion depth profiles of the thin film Al-7 wt \% $\mathrm{Cu}$ sample C. (a) Depth profile recorded inside the exposed area and (b) Depth profile recorded in an unexposed area.

(b)

examination of the depth profiles in Fig. 4. Some of the pits have slightly elevated $\mathrm{Cu}$ content as indicated by the ${ }^{63} \mathrm{Cu}^{-}$image (orange arrows). This might be associated with the $\mathrm{Al}_{2} \mathrm{Cu}$ particles or with $\mathrm{Cu}$ enrichment resulting from preferential dissolution of $\mathrm{Al}$.

Pits with sizes ranging between 50 and $500 \mathrm{~nm}$ and at a density of about $3 \mu \mathrm{m}^{-2}$ are also evident in an AFM image of the exact same area (Fig. 6). All the pits are about $15 \mathrm{~nm}$ deep suggesting that they do not extend to the $\mathrm{SiO}_{2} / \mathrm{Si}$ substrate. However, as described above, the pits likely reach the substrate but contain a considerable amount of corrosion product. The higher density of pits observed with AFM compared with SI images is due to the better lateral resolution of the AFM that allows detection of pits with size lower than $150 \mathrm{~nm}$ (which is the lateral resolution of the ToF-SIMS spectrometer used). Nevertheless, the density of pits in the AFM image with diameter greater than $150 \mathrm{~nm}$, about $0.9 \mu \mathrm{m}^{-2}$, is in good agreement with the density of pits detected on the SE or SI images.
Bulk sample.-The bulk sample exhibited a rougher surface as a result of the polishing procedure utilized (Fig. 7a). A dense distribution of $\mathrm{Al}_{2} \mathrm{Cu}$ particles can be observed on the sample surface in the thermally-treated condition (a). The particles were larger than those in the thin film sample. Many were almost round with diameter about $1 \mu \mathrm{m}$, but many were elongated along the polishing direction, suggesting that the polishing scratches were preferred nucleation sites (recall that polishing was performed prior to the aging treatment). The FIB cross-section in Fig. $7 b$ shows that a precipitate free zone (PFZ) existed below the surface particles. The sample was tilted by $52^{\circ}$ in the SEM image, so the average thickness of the surface particles is about $300 \mathrm{~nm}$ and the depth of the PFZ is about 1.6 $\mu \mathrm{m}$. Below the PFZ, the particles are lathe-like with crystallographic orientation. Other FIB sections (not presented) show large precipitates at subsurface grain boundaries and PFZs of similar dimensions in the grain interiors around those grain boundary particles. 


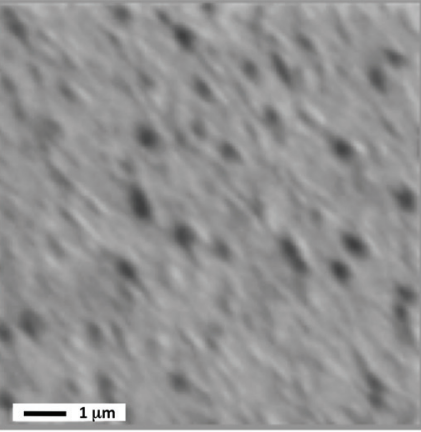

(a)
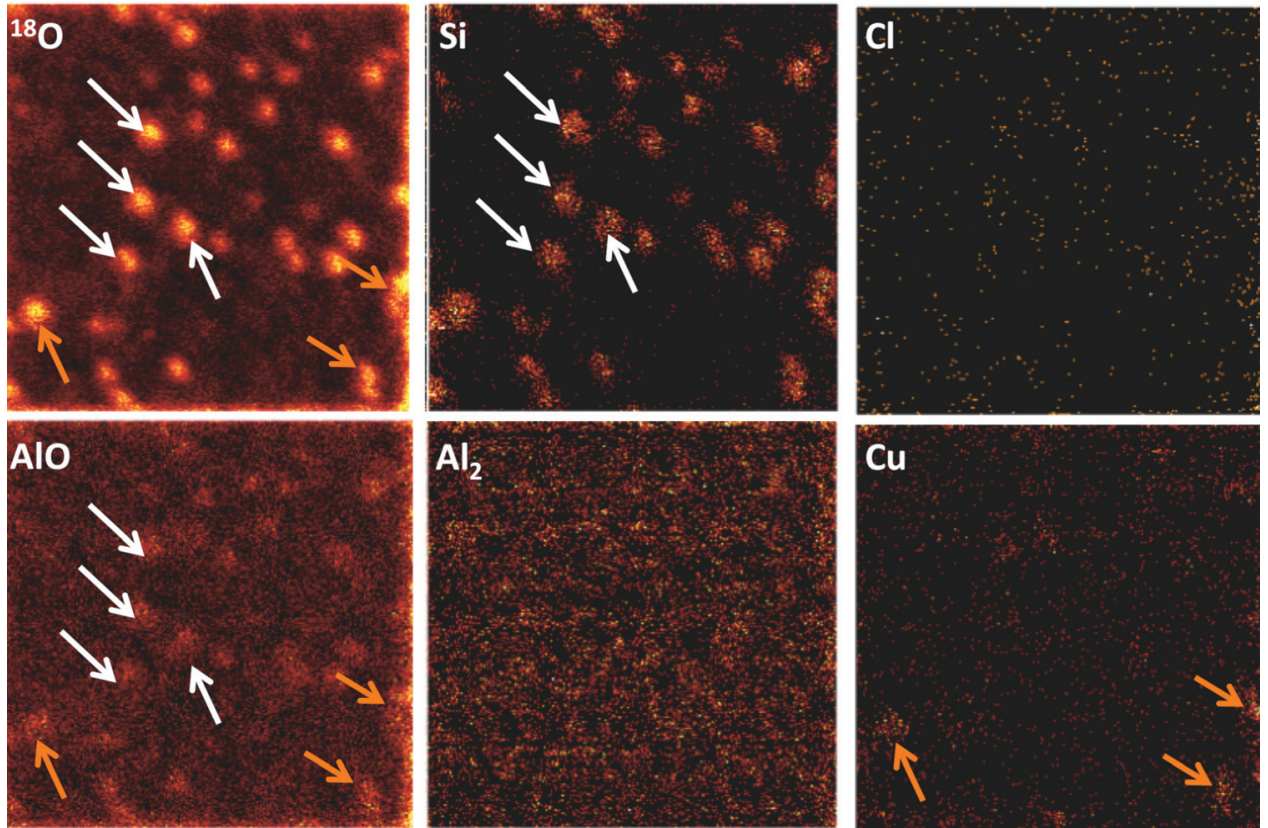

(b)

SIMS analysis was performed on this sample to investigate the ability of the ToF-SIMS mapping to identify larger $\theta$ phase particles. Figure 8 shows a ToF-SIMS negative ion depth profile of the bulk sample D. The oxide layer thickness corresponds to a $\mathrm{Cs}^{+}$sputtering time of $\sim 350 \mathrm{~s}$. According to the sputtering conditions used $\left(500 \times 500 \mu \mathrm{m}^{2}, 47.4 \mathrm{nA}, 0.5 \mathrm{keV}\right)$ and to the sputter yield, the oxide layer thickness is estimated to be $\sim 8.8 \mathrm{~nm}$. ToF-SIMS mapping was performed on this sample as was done for the thin film sample. The maps at the surface indicated a homogeneous $\mathrm{Al}$ oxide surface, identical to the thin film sample. Figure 9a shows negative ion maps after $220 \mathrm{~s}$ of sputtering, which is in the region of the metal/oxide interface. $\mathrm{Cu}$ localization is also observed in this sample at the interface, and the $\mathrm{Cu}$-rich regions are larger and elongated, similar to the shapes observed for $\theta$ phase in the SEM (Fig. 7). Figure $9 \mathrm{~b}$ shows negative ion maps after $800 \mathrm{~s}$ of sputtering, which is below the region of the metal/oxide interface. Bright $\mathrm{Cu}$ spots are seen at the site of some of the spots seen in the $220 \mathrm{~s}$ maps, indicating that the ToF-SIMS technique can visualize large $\theta$ phase particles in the metal matrix. However, the boundary between the $\theta$ phase and the matrix is not very clear.

\section{Discussion}

An oxide film was formed on the surface of the $\mathrm{Al}-3.5 \% \mathrm{Cu}$ thin films as the result of exposure of the as-deposited films to oxygen and then subsequent thermal treatment in air. The as-deposited film was likely a homogeneous solid solution of $\mathrm{Al}$ and $\mathrm{Cu}$, which would have oxidized uniformly in the oxygen environment. Any further
Figure 5. (Color online) Secondary electron image (a) and secondary ion images (b) recorded at the same location, showing the pits formed on the Al-7 wt \% Cu sample C. 


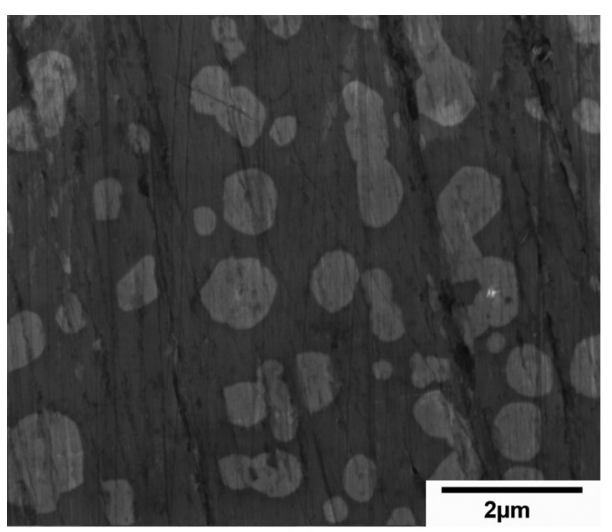

(a)

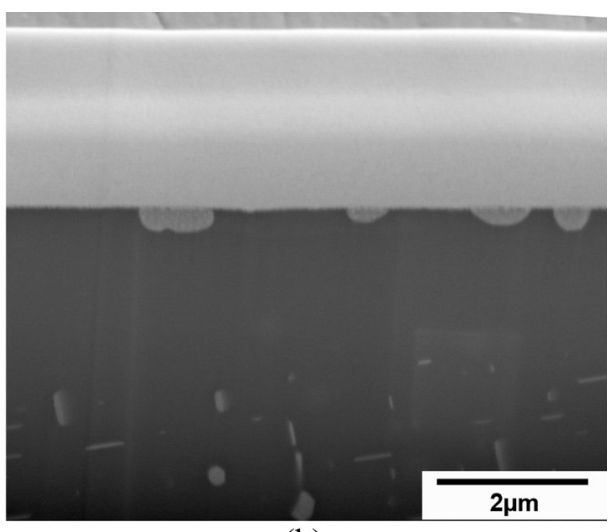

(b)
Figure 7. SEM images of bulk sample after aging treatment. (a) Top view of sample showing distribution of micron-sized $\mathrm{Al}_{2} \mathrm{Cu}$ particles. (b) FIB cross section showing depth distribution of $\mathrm{Al}_{2} \mathrm{Cu}$ particles with a precipitate-free zone. oxidation during the thermal treatment happened simultaneously with the development of the microstructure to the condition of $\theta$ phase in the $\mathrm{Cu}$-depleted matrix. The SIMS maps of samples in condition (a), the as-heat-treated condition, indicate that the outer part of the oxide is homogeneous $\mathrm{Al}$ oxide. Preferential oxidation of $\mathrm{Al}$ is expected, and the development of the heterogeneous microstructure did not affect the oxide composition. The SIMS depth profiles show a metallic $\mathrm{Cu}$ peak at the metal/oxide interface, which is likely associated with the enrichment of $\mathrm{Cu}$ that would result from preferential $\mathrm{Al}$ oxidation.

The SIMS compositional maps indicate that localized, metallic $\mathrm{Cu}$-rich regions are formed at the oxide/metal interface that are approximately of the size of the $\theta$ phase particles. ToF-SIMS analyses deeper into the metal do not show localized $\mathrm{Cu}$ enrichment associated with the $\theta$ phase particles. This was unexpected since $\theta$ phase particles are observed by cross-sectional SEM and TEM to develop through-thickness on the $\mathrm{Al}-\mathrm{Cu}$ thin films as shown in Fig. 1c. This suggests that the localized $\mathrm{Cu}$ enrichment at the interface is not associated with underlying $\theta$ phase particles. However, although SIMS maps in the metal show no evidence of $\mathrm{Cu}$ localization anywhere, it is important to note, that in the conditions used here for ToF-SIMS analyses (i.e. negative polarity), the secondary ion yield is much higher for oxide matrices than for metal matrices, so it is likely that the small $\theta$ phase particles are beyond the spatial resolution $(\sim 150 \mathrm{~nm})$ of the SIMS tool in negative polarity. The larger $\theta$ phase particles formed at the surface of the bulk Al-Cu alloy given the same heat treatment could be observed in the SIMS maps but their borders were not very distinct (Fig. 9).

Given this understanding of the limitations of the SIMS mapping, different explanations for the localization of $\mathrm{Cu}$ observed at the oxide/metal interface are possible. One possibility is that a heterogeneous $\mathrm{Cu}$ enriched layer is formed (as a result of the preferential oxidation of $\mathrm{Al}$ ), when the as-deposited homogeneous $\mathrm{Al}-\mathrm{Cu}$ thin film was exposed to oxygen. These $\mathrm{Cu}$ rich regions might have acted as nucleation sites for $\theta$ phase particles during the subsequent anneal or they might not have been associated with the $\theta$ phase particles; because it was not possible to observe the particles in the metal matrix, this association could not be proved for the thin films. On the other hand, the $\mathrm{Cu}$ enrichment at the oxide/metal interface of the bulk sample seemed to be associated with underlying $\theta$ phase particles.

An alternative explanation is that further oxidation occurred during the thermal treatment so that the heterogeneous microstructure could affect the development of the oxide/metal interface. The peak in the $\mathrm{Cu}$ signal at the oxide/metal interface would then result from a thinner $\mathrm{Al}$ oxide above the particles, with an enhancement of the ionisation of $\mathrm{Cu}$ in the $\theta$ phase particles at the oxide interface.

Regardless of the explanation for their formation, the localized $\mathrm{Cu}$-rich regions indicate that there are local variations in the oxide

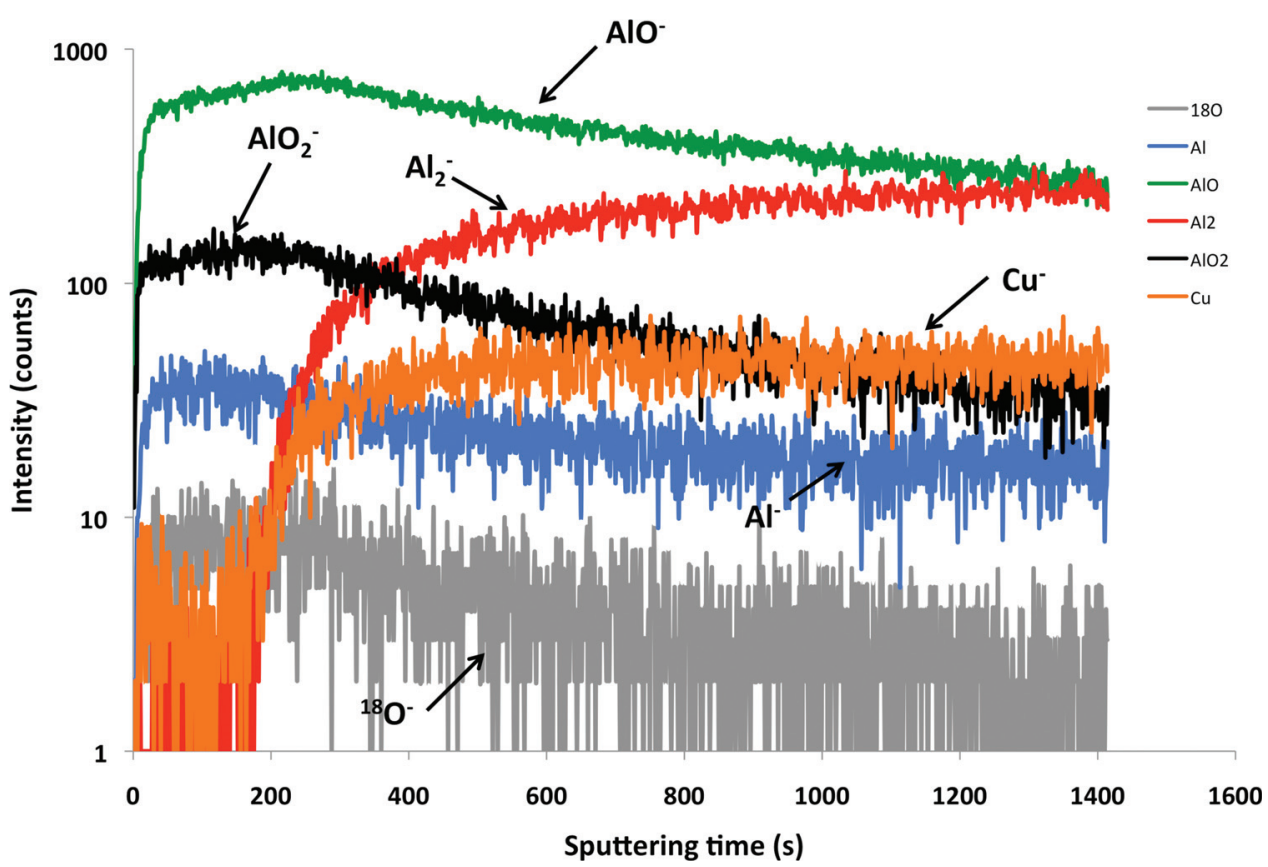

Figure 8. (Color online) ToF-SIMS negative ion depth profile obtained on the bulk Al-4 wt \% Cu sample. 

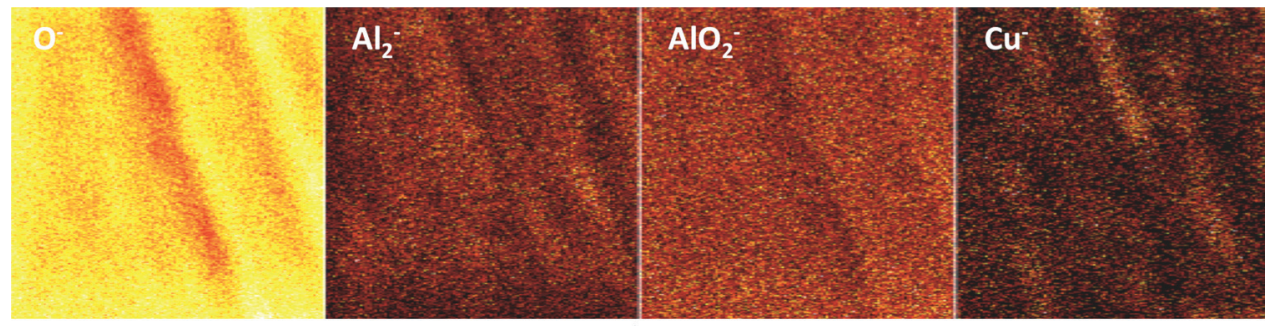

a)
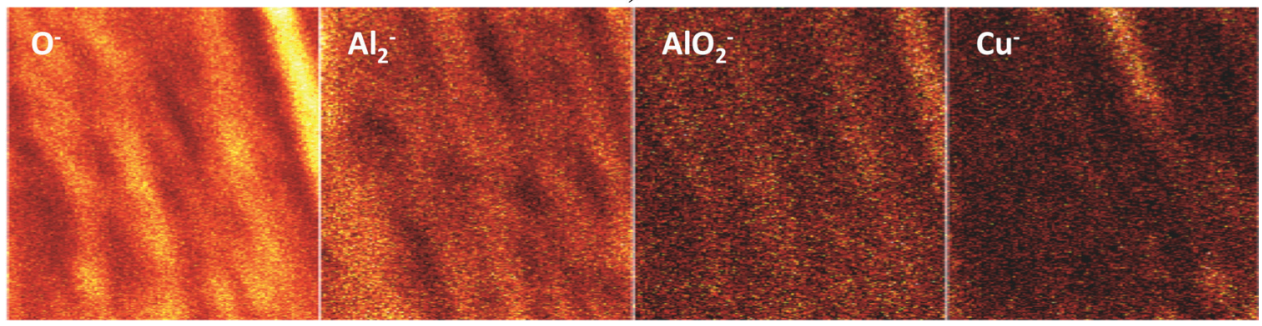

Figure 9. (Color online) ToF-SIMS negative ion images of ${ }^{18} \mathrm{O}^{-}, \mathrm{Al}_{2}^{-}, \mathrm{AlO}_{2}^{-}$and $\mathrm{Cu}^{-}$recorded on the bulk Al-4 wt $\% \mathrm{Cu}$ sample (a) after $220 \mathrm{~s}$ of sputtering, (b) after $800 \mathrm{~s}$ of sputtering.

b)

thickness and/or interfacial composition. It is reasonable that these regions are more catalytic than areas with no $\mathrm{Cu}$ enrichment, so that they could be preferred sites for the cathodic reaction. Alternatively, a thinner oxide above the $\mathrm{Cu}$-rich regions would likely be more susceptible to localized corrosion in a chloride environment. However, within the sensitivity of the SIMS technique, no evidence for differences in composition among $\mathrm{Cu}$-rich regions was observed that could explain why attack was found only at some particles and not others during localized corrosion.

\section{Conclusions}

ToF-SIMS imaging of model thin film Al-Cu alloys showed that in the absence of localized corrosion, pure $\mathrm{Al}$ oxide exists above both the intermetallic $\mathrm{Al}_{2} \mathrm{Cu}$ particles and the surrounding matrix. Depth profiling, combined with ion imaging as a function of depth, showed localized enrichment of metallic $\mathrm{Cu}$ at the metal/oxide interface. The size and density of these $\mathrm{Cu}$-rich regions corresponded to that of the intermetallic particles. Following exposure to an aggressive environment, where localized corrosion was initiated, the pit density closely matched that of the $\mathrm{Cu}$-rich interfacial regions. The locally thinner oxide in these regions could provide initiation sites for localized corrosion.

\section{Acknowledgments}

Region Ile-de-France is acknowledged for partial support for the ToF-SIMS equipment. The authors thank R. G. Copeland and J. Rivera for the Al-Cu thin film deposition, and M. Rye for the thin film SEM characterization. Sandia National Laboratories is a multiprogram laboratory operated by Sandia Corporation, a wholly owned subsidiary of Lockheed Martin company, for the U.S. Department of Energy's National Nuclear Security Administration under contract DE-AC04-94AL85000. NM's research was supported by the U.S. Department of Energy, Office of Basic Energy Sciences, Division of Materials Science and Engineering, under Contract DE-AC02-98CH1088. Financial support of GSF by the
University Pierre and Marie Curie during his stay at ENSCP in Paris as guest professor is gratefully acknowledged.

École Nationale Supérieure de Chimie de Paris assisted in meeting the publication costs of this article.

\section{References}

1. J. R. Galvele and S. M. DeMicheli, Corros. Sci., 10, 795 (1970).

2. I. L. Muller and J. R. Galvele, Corros. Sci., 17, 179 (1977).

3. J. R. Scully, R. P. Frankenthal, K. J. Hanson, D. J. Siconolfi, and J. D. Sinclair, J. Electrochem. Soc., 137, 1365 (1990).

4. J. R. Scully, D. E. Peebles, A. D. Romig, Jr., D. R. Frear, and C. R. Hills, Metall. Trans. A, 23A, 2641 (1992).

5. G. S. Chen, M. Gao, and R. P. Wei, Corrosion, 52, 8 (1996)

6. R. G. Buchheit, R. P. Grant, P. F. Hlava, B. Mckenzie, and G. L. Zender, J. Electrochem. Soc., 144, 2621 (1997).

7. C. Blanc, B. Lavelle, and G. Mankowski, Corros. Sci., 39, 495 (1997).

8. C.-M. Liao, J. M. Olive, M. Gao, and R. P. Wei, Corrosion, 55, 451 (1998).

9. R. P. Wei, C.-M. Liao, and M. Gao, Metall. Mater. Trans. A, 29, 1153 (1998).

10. T. Suter and R. C. Alkire, J. Electrochem. Soc., 148, B36 (2001).

11. G. O. Ilevbare, O. Schneider, R. G. Kelly, and J. R. Scully, J. Electrochem. Soc., 151, B453 (2004)

12. O. Schneider, G. O. Ilevbare, J. R. Scully, and R. G. Kelly, J. Electrochem. Soc., 151, B465 (2004).

13. J. R. Scully, T. O. Knight, R. G. Buchheit, and D. E. Peebles, Corros. Sci., 35, 185 (1993).

14. C.-M. Liao and R. P. Wei, Electrochim. Acta, 45, 881 (1999).

15. N. Birbilis and R. G. Buchheit, J. Electrochem. Soc., 152, B140 (2005).

16. N. Birbilis and R. G. Buchheit, J. Electrochem. Soc., 155, C117 (2008).

17. M. A. Alodan and W. H. Smyrl, J. Electrochem. Soc., 145, 1571 (1998).

18. N. Missert, J. C. Barbour, R. G. Copeland, J. E. Mikkalson, JOM, 53, 34 (2001).

19. M. B. Vukmirovic, N. Dimitrov, and K. Sieradzki, J. Electrochem. Soc., 149, B428 (2002).

20. A. Kelly and R. B. Nicholson, Prog. Mater. Sci., 10, 151 (1963).

21. N. Missert, R. G. Copeland, P. Kotula, J. J. Hren, and J. Rivera, Unpublished.

22. L. Lacroix, L. Ressier, C. Blanc, and G. Mankowski, J. Electrochem. Soc., 155, C131 (2008).

23. Y. Liu, P. Bailey, T. C. Q. Noakes, G. E. Thompson, P. Skeldon, and M. R Alexander, Surf. Interface Anal., 36, 339 (2004).

24. Y. Liu, M. A. Arenas, S. J. Garcia-Vergara, T. Hashimoto, P. Skeldon, G. E. Thompson, H. Habazaki, P. Bailey, and T. C. Q. Noakes, Corros. Sci., 50, 1475 (2008).

25. H. H. Strehblow, C. M. Melliar-Smith, and W. M. Augustyniak, J. Electrochem Soc., 125, 915 (1978). 